\title{
Prescription Stimulant-Induced Neurotoxicity: Mechanisms, outcomes, and relevance to $\mathrm{ADHD}$
}

\author{
Joshua Ellis Tucker", MPH
}

\begin{abstract}
Attention-deficit/hyperactivity disorder (ADHD) is a relatively prevalent neuropsychiatric and neurodevelopmental condition characterized in the Diagnostic and Statistical Manual of Mental Disorders, Fifth Edition (DSM-5) as difficulty sustaining attention and maintaining tasks at hand, heightened distractibility, and other deficits in executive functioning. Prescription stimulants-amphetamine (AMP) and methylphenidate (MPH) - are the first-line treatment(s) for ADHD in both pediatric and adult populations and exist in many formulations. Troublingly, the non-medical use (NMU) of amphetamine and methylphenidate is more prevalent in the American population, especially on college and university campuses, than the condition of interest. The neurotoxicological profile and NMU epidemiology of prescription stimulants is of direct relevance to primary care physicians and psychiatrists as they are the providers most frequently tasked with the treatment of ADHD and the surveillance of substance misuse behaviors in the young adult population. As comprehensive literature reviews of the mechanisms and potential adverse sequelae of prescription stimulant-induced neurotoxicity intended for medical clinicians have been quite sparse in the last decade-especially given the gravity of the issue - this article includes a brief primer on ADHD etiology and pathophysiology; considers the current state of NMU epidemiology; reviews the mechanisms of action of AMP and MPH; and, finally, summarizes known molecular and clinical manifestations of AMP and MPH neurotoxicity.
\end{abstract}

\section{Keywords}

attention deficit disorder with hyperactivity $\bullet$ prefrontal cortex $\bullet$ amphetamine $\bullet$ central nervous system stimulants $\bullet$ students $\bullet$ young adults $\bullet$ prescription drug misuse

"University of Michigan School of Public Health, tuckjosh@umich.edu (1D) https://orcid.org/0000-0003-1548-1495

doi: $10.3998 / \mathrm{mjm} .1437$

Conflicts of interest:

The author has no conflicts of interest to report 


\section{Introduction}

The clinical utility of prescription stimulants for the treatment of attention-deficit/hyperactivity disorder (ADHD) is well characterized and robust. ${ }^{1}$ ADHD is a persistent and pervasive neurodevelopmental disorder with an etiology influenced by the interplay of environmental and genetic factors. ${ }^{2}$ The cardinal symptoms of ADHD-hyperactivity, impulsivity, and/or inattention - are usually noticed by parents, teachers, and/or other caregivers in mid- to late childhood. Symptoms may cause noticeable impairments in social interaction and limit effective communication, social cooperation, and academic success. ${ }^{3,4}$ Early diagnosis by qualified mental health professionals (eg, psychotherapists, psychiatrists, behavioral neurologists) is associated with greater long-term symptom management. ${ }^{5}$ Interestingly, up to $85 \%$ of patients diagnosed with ADHD early in life continue to have symptoms into adulthood, meaning long-term treatment consideration is likely necessary. ${ }^{6-9}$ Amphetamine (AMP) salts and methylphenidate $(\mathrm{MPH})$, both prescription stimulants with many formulations (Table 1), have been recommended as first-line treatments for ADHD in both pediatric and adult populations in the

Table 1. FDA-Approved Formulations for the Treatment of ADHD

\begin{tabular}{|c|c|c|}
\hline Trade name & Dosage & $\begin{array}{l}\text { Maximum } \\
\text { recommended }\end{array}$ \\
\hline \multicolumn{3}{|l|}{ Methylphenidate } \\
\hline Focalin XR & 5-40 mg capsules & $1 \mathrm{mg} / \mathrm{kg}$ or $30 \mathrm{mg} /$ day \\
\hline Concerta & 18-54 mg tablets & $2 \mathrm{mg} / \mathrm{kg}$ or $72 \mathrm{mg} /$ day \\
\hline Ritalin LA & 10-40 mg capsules & $2 \mathrm{mg} / \mathrm{kg}$ or $60 \mathrm{mg} /$ day \\
\hline Metadate CD & 10-60 mg capsules & $2 \mathrm{mg} / \mathrm{kg}$ or $60 \mathrm{mg} /$ day \\
\hline Daytrana & 10-30 mg patches & $30 \mathrm{mg} /$ day \\
\hline Ritalin SR & $20 \mathrm{mg}$ tablets & $2 \mathrm{mg} / \mathrm{kg}$ or $60 \mathrm{mg} /$ day \\
\hline Methylin ER & 10-20 mg tablets & $2 \mathrm{mg} / \mathrm{kg}$ or $60 \mathrm{mg} /$ day \\
\hline Quillivant & $25 \mathrm{mg} / 5 \mathrm{~mL}$ suspension & $60 \mathrm{mg}$ QAM \\
\hline Focalin & 2.5-10 mg tablets & $2 \mathrm{mg} / \mathrm{kg}$ or $60 \mathrm{mg} /$ day \\
\hline Ritalin & 5-20 mg tablets & $2 \mathrm{mg} / \mathrm{kg}$ or $60 \mathrm{mg} /$ day \\
\hline Methylin & $\begin{array}{l}5-20 \mathrm{mg} \text { tablets or } \\
5-10 \mathrm{mg} / 5 \mathrm{~mL} \text { solution }\end{array}$ & $2 \mathrm{mg} / \mathrm{kg}$ or $60 \mathrm{mg} /$ day \\
\hline \multicolumn{3}{|l|}{ Amphetamine } \\
\hline Vyvanse & 10-70 mg capsules & $1 \mathrm{mg} / \mathrm{kg}$ or $70 \mathrm{mg} /$ day \\
\hline Adderall XR & 5-30 mg capsules & $1 \mathrm{mg} / \mathrm{kg}$ or $30 \mathrm{mg} /$ day \\
\hline Dexedrine & 5-15 mg capsules & $1 \mathrm{mg} / \mathrm{kg}$ or $30 \mathrm{mg} /$ day \\
\hline Adderall & $5,7.5,10,12.5,15,20,30 \mathrm{mg}$ tablets & $1 \mathrm{mg} / \mathrm{kg}$ or $30 \mathrm{mg} /$ day \\
\hline Dextroamphetamine & 5-10 mg tablets & $1 \mathrm{mg} / \mathrm{kg}$ or $30 \mathrm{mg} / \mathrm{day}$ \\
\hline ProCentra & $5 \mathrm{mg} / 5 \mathrm{~mL}$ solution & $1 \mathrm{mg} / \mathrm{kg}$ or $30 \mathrm{mg} / \mathrm{day}$ \\
\hline
\end{tabular}


United States for decades, although adjunctive behavioral therapy may produce even better outcomes in adults. ${ }^{1,5-7,10-14}$

Although the employment of stimulants in the treatment of nosologic predecessors to ADHD has been commonplace since the mid-20th century, ${ }^{8,15}$ adequate comprehensive consideration of the potential neurological sequelae of long-term stimulant use, prescribed or otherwise, is noticeably lacking in the literature. Alarmingly, the Schedule II status of stimulant medications indicates their abuse and dependency potential is similar to the medications implicated in the current opioid epidemic. These factors should be of great importance to the interested clinical, toxicological, and epidemiological communities given the popular ease of access to, high prevalence of, and largely unknown long-term neurological sequelae of prescription stimulant use and misuse that I consider in this article. Importantly, the prevalence of ADHD is estimated to be between 5\% and 10\% in American children and 2.8\% and 5.2\% in adults, yet the prevalence of non-medical use (NMU) of stimulants is estimated to exceed that of the very condition(s) for which they are indicated. ${ }^{10,11,16-20}$ If prescription stimulants are more prevalent among the population than the condition(s) they are prescribed for, clinicians and epidemiologists should know what to look for when future patients without documented ADHD present with symptoms of dopaminergic and noradrenergic pathology. The same is true for those with a history of ADHD treatment, although historical stimulant use would hopefully be documented. Similar to medications approved for any variety of condition, NMU of stimulants indicated for ADHD is associated with a variety of adverse effects, and the potential for serious harm in

Table 2. DSM-5 Diagnostic Criteria for ADHD by Presentation

\begin{tabular}{|l|l|}
\hline Presentation & \multicolumn{1}{c|}{\begin{tabular}{c}
\multicolumn{1}{c|}{ DSM-5 diagnostic criteria } \\
( $\mathbf{5}$ of the following for at least $\mathbf{6}$ months in adults)
\end{tabular}} \\
\hline $\begin{array}{l}\text { Predominantly } \\
\text { inattentive }\end{array}$ & $\begin{array}{l}\text { - Frequent failure to pay attention to detail in work, academic, or social } \\
\text { settings } \\
\text { - Difficulty sustaining attention in tasks or play activities } \\
\text { - Frequently fails to listen when spoken to directly } \\
\text { - Difficulty managing and organizing tasks and activities } \\
\text { - Tends to avoid tasks requiring sustained mental effort } \\
\text { - Frequently loses materials necessary for daily tasks } \\
\text { - Easily distracted by extraneous stimuli }\end{array}$ \\
\hline - Often forgetful of daily activities
\end{tabular}


the long term remains poorly characterized. ${ }^{21}$ This article includes a brief primer on ADHD etiology and pathophysiology; considers the current state of NMU epidemiology; reviews the mechanisms of action of AMP and MPH; and, finally, summarizes known molecular and clinical manifestations of AMP and MPH neurotoxicity.

\section{Primer on ADHD Etiology and Pathophysiology}

ADHD (previously called attention-deficit disorder) is characterized by pervasive cognitive, behavioral, and emotional dysfunction. ${ }^{4,22}$ There are three clinical presentations of ADHD classified in the Diagnostic and Statistical Manual of Mental Disorders, Fifth Edition (DSM-5, Table 2), with the combined presentation being the most prevalent (62\%). ${ }^{23}$ Although roughly $75 \%$ of the risk for ADHD is attributed to genetics, large genome-wide association studies have been mostly unsuccessful in convincingly detecting DNA polymorphisms specifically associated with ADHD. ${ }^{2,20,24}$ Thankfully, this may be changing as recent work has found variants on $F O X P_{2}$, $S O R C S_{3}$, and DUSP6, among other genes, to be associated with a 1.077 to 1.198 increased odds of ADHD development. ${ }^{25}$ Variants of genes involved in dopamine transmission, $D R D_{4}, D R D_{5}$, $C O M T$, and $D A T_{I}$, among others, have been shown to be associated with ADHD, providing evidence for the catecholamine dysregulation hypothesis of ADHD.,24,26-31 Norepinephrine (NE) signaling is believed to be attenuated alongside dopamine (DA) in ADHD, which is likely the reason the NE reuptake inhibitor atomoxetine alleviates ADHD symptoms in some with the condition. ${ }^{27,32-34}$ Inhibition of neurotransmitter transporters, a mechanism of action of both $\mathrm{AMP}$ and $\mathrm{MPH}$, prevents presynaptic reuptake of DA and NE molecules, thus allowing postsynaptic receptors greater access to their respective ligands. ${ }^{35-37}$ The greater effectiveness of AMP and $\mathrm{MPH}$ compared to atomoxetine in individuals with ADHD is likely due to the frequent functional and anatomical changes seen in dopamine transport (DAT) in dopaminergic regions such as the frontal cortex, striatum, and basal ganglia compared to noradrenergic regions. ${ }^{1,38-42}$ Serotonergic, acetylcholinergic, opioid, and glutamatergic signaling pathways are implicated in the pathophysiology of $\mathrm{ADHD}$, as well, but current pharmacotherapeutic options target mainly $\mathrm{NE}$ and DA. ${ }^{43,44}$ As the etiology of ADHD is not unitary, it is likely that causal pathways will be interactive and dynamic; genetic, structural, functional, environmental, and social factors each appear to contribute to ADHD pathophysiology. ${ }^{45}$ Importantly, though the mechanisms of action of stimulants are identical in those with and without ADHD, their known outcomes are not. ${ }^{18,42,46}$

\section{Methods}

PubMed was used to search the literature for English-language articles published between 2005 and April 2020. The cutoff year of 2005 was selected as the novel Adult ADHD SelfReport Scale, version 1.1, the first adequate instrument used in the assessment of adult ADHD symptomatology, entered use in the World Health Organization's World Mental Health Survey Initiative that year. ${ }^{47}$ Search terms including ADHD, attention deficit byperactivity disorder, amphetamine, and methylphenidate were used alone and in combination with toxicity, epidemiology, adverse effects, etiology, pharmacology, and/or misuse. The additional filters of journal article and review were used to identify peer-reviewed articles addressing amphetamine and/or methylphenidate toxicology, misuse, and pharmacology, as well as ADHD treatment, etiology, pathophysiology, and epidemiology. The reference lists of retrieved articles were regularly handsearched for other relevant reviews, trials, or original research to identify additional records for use. Titles, abstracts, and full texts that resulted from keyword searches were reviewed briefly to 
determine topical relevance, and the journal an article was published in was checked for quality using InCites Journal Citation Reports and/or Google Scholar Metrics. Individual articles were rated for quality using the McMaster University Effective Public Health Practice Project tool when deemed appropriate. ${ }^{48}$ To reduce the number of publications to review, the most up-todate review papers were used whenever possible. Publications were selected according to professional judgment of quality, relevance to MPH/AMP toxicology or pharmacology, and whether findings had clinical relevance. Older publications, such as a 1981 report on MPH hallucinosis, were included when necessary. ${ }^{49}$

Exclusion of an article occurred if (1) it pertained to ADHD comorbid with a diagnosed psychiatric or developmental disorder (eg, autism spectrum disorder, obsessive-compulsive disorder, mood disorder), (2) concerned the effectiveness of ADHD interventions used outside mainstream medicine (eg, fish oil, ginger), (3) pertained to toxicity profiles beside neurological, (4) focused on psychosocial management of $\mathrm{ADHD}$, or (5) concerned ADHD secondary to some other medical condition. The PRISMA flow diagram for this review's selection procedure is presented in Figure $1 .{ }^{50}$ After applying inclusion and exclusion criteria and hand-searching reference lists from important articles in the literature, a total of 488 articles were considered for review. Of the 5006 articles initially yielded during the search, 114 were used in authoring this article.

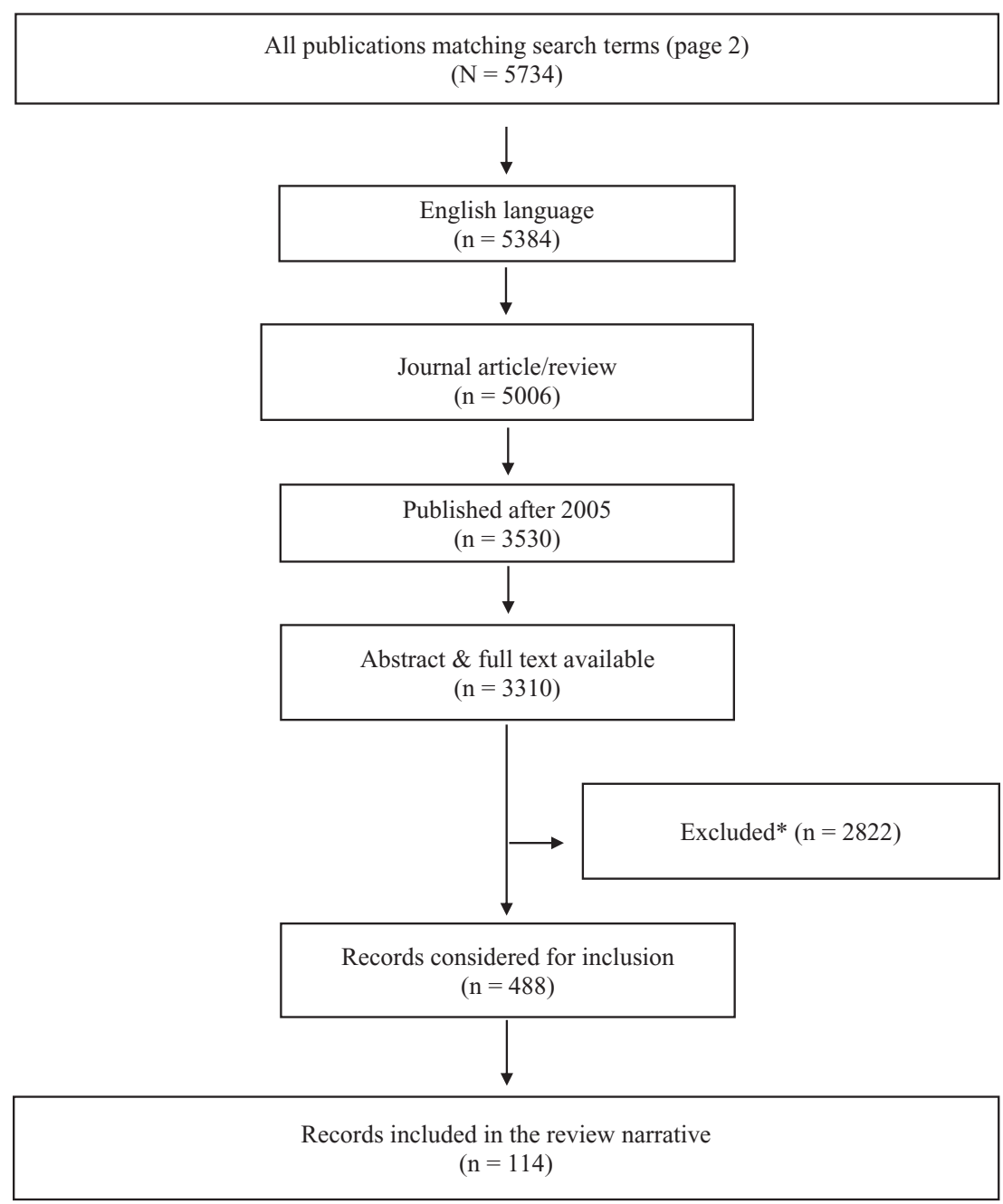

Figure 1. Flow Diagram of Records Identified, Screened, and Included.

*Excluded due to topical irrelevance, low publication quality, or publication type 


\section{Non-Medical Use Epidemiology}

Recognition by the psychiatric and behavioral medicine communities that ADHD persists into adulthood in at least a large proportion of cases has increased subsequent availability of stimulant medications in the adult population. ${ }^{51}$ Given the strong motivation by young adults (aged 18 to 25 years) - many of whom are in college - to perform well academically, the positive effects on cognitive functioning in those who use stimulants for ADHD are plausibly expected to produce similar effects in anyone who uses them. As stimulant medications are known to boost working memory, processing speed, sociability, attention, etc in patients with ADHD, the average individual engaging in NMU simply (and erroneously) expects those clinical benefits to translate into improved test scores, more hours spent studying, and cognitive stamina. $^{26}$

Misuse of stimulants, defined as the NMU of prescription medications used to treat ADHD and other conditions, is especially prevalent on American college campuses. ${ }^{52}$ American young adults misuse prescription stimulants significantly more frequently each year compared to the general adult population. ${ }^{19,53-55}$ Prescription stimulants are reported to be easily accessible on college campuses, and, as neural networks underlying decision-making and risk assessment are not fully mature until the mid-twenties, so is the tendency to experiment with stimulants or other substances for perceived benefit. ${ }^{56-58}$ Young adulthood is the period wherein addiction and neuropsychiatric conditions are most likely to become symptomatic, making experimentation with powerful prescription medications and psychotropic substances rife with potential danger. ${ }^{56}$ Alarmingly, the results of the 2018 National Survey on Drug Use and Health (NSDUH) showed that stimulant misuse eclipsed opioid misuse for the second year in a row, with $6.5 \%$ and $5.5 \%$ of young adults between 18 and 25 years of age misusing stimulants and opioids, respectively. ${ }^{59}$

Most non-medical users of stimulants report obtaining the medication from their family, friends, or peers. ${ }^{18,19,60}$ Interestingly, though effective long-term pharmacological management of ADHD is associated with overall decreased odds of developing a substance use disorder, ${ }^{61-63}$ between $4 \%$ and $35 \%$ of college students diagnosed with ADHD report previous NMU of their medication. ${ }^{18}$ Using data published between 2005 and 2019, I calculated the pooled prevalence of NMU among Americans aged 18 to 25 years, regardless of their educational status (Table 3). Although estimates ranged from $2 \%$ to $31 \%,{ }^{60,85}$ the estimated mean pooled prevalence of NMU among American young adults, including college students, is 9.21\% (Table 3). The 2018 NSDUH found that compared to adults aged 26 years and older, young adults reported NMU between 3 times and 4 times more frequently. ${ }^{59}$ Furthermore, Compton, the deputy director of the NIDA, and colleagues recently found young adults to have roughly 5 times the odds of initiating NMU than older adults. ${ }^{19,59}$ Whether there is a statistically significant trend toward higher prevalence of NMU among the young adult population is difficult to ascertain given the wide range of estimates in the literature and lack of uniform measurement method. Although the NSDUH found a relatively stable 4-year prevalence of NMU among young adults, peer-reviewed publications almost uniformly vary from the official reports. ${ }^{59}$ It is unclear why a complete picture of NMU among young adults has remained so elusive. Perhaps this is due to geographical differences or cultural idiosyncrasies among individual college campuses. Furthermore, this variance is multifactorial: definitions (or lack thereof) of NMU, sample size, classification of drugs, and methodology tend to differ from one study to the next. 
Table 3. NMU Prevalence in Young Adults (including college students) Reported Between 2005 and 2019

\begin{tabular}{|c|c|c|}
\hline Source & $\mathrm{N}$ & Prevalence \\
\hline Teter et al, 2005 & 9161 & $5.4 \%$ \\
\hline Teter et al, 2006 & 4580 & $5.9 \%$ \\
\hline Lord et al, 2009 & 950 & $5.0 \%$ \\
\hline Weyandt et al, 2009 & 363 & $8.9 \%$ \\
\hline Upadhyaya et al, 2010 & 3307 & $2.1 \%$ \\
\hline Rabiner et al, 2010 & 3407 & $8.9 \%$ \\
\hline Clegg-Kraynok et al, 2011 & 492 & $7.0 \%$ \\
\hline Garnier-Dykstra et al 2012 & 1253 & $17.7 \%$ \\
\hline Lookatch et al, 2012 & 206 & $26.1 \%$ \\
\hline Bavarian et al, 2013 & 520 & $25.6 \%$ \\
\hline Hartung et al, 2013 & 1153 & $25.9 \%$ \\
\hline Webb et al, 2013 & 144 & $15.0 \%$ \\
\hline Wasserman et al, 2014 & 380 & $15.2 \%$ \\
\hline Messina et al, 2014 & 1016 & $25.4 \%$ \\
\hline Meisel \& Goodie, 2015 & 279 & $17.2 \%$ \\
\hline Cassidy et al, 2015 & 2073 & $11.3 \%$ \\
\hline Gallucci et al, 2015 & 1020 & $12 \%$ \\
\hline Weyandt et al, 2016 & 807 & $5.9 \%$ \\
\hline Bavarian et al, 2017 & 554 & $16.6 \%$ \\
\hline Kinman et al, 2017 & 988 & $23 \%$ \\
\hline McCabe et al, 2018 & 4004 & $7.3 \%$ \\
\hline Le et al, 2018 & 939 & $11.4 \%$ \\
\hline Schulenberg et al, 2019 & 900 & $8.3 \%$ \\
\hline Pooled Prevalence & 38,496 & $9.21 \%$ \\
\hline
\end{tabular}

\section{Mechanisms of Action}

The therapeutic effect of stimulants provides for greater attention to tasks at hand, access to working memory, planning, reward processing, and other relevant tasks that constitute executive functioning. ${ }^{7}$ The two neurotransmitters associated with executive functioning, DA and NE, are highly concentrated in the prefrontal cortex (PFC) and act intimately in tandem. AMP and $\mathrm{MPH}$ are known to enhance DA and $\mathrm{NE}$ neurotransmission in the PFC by increasing 

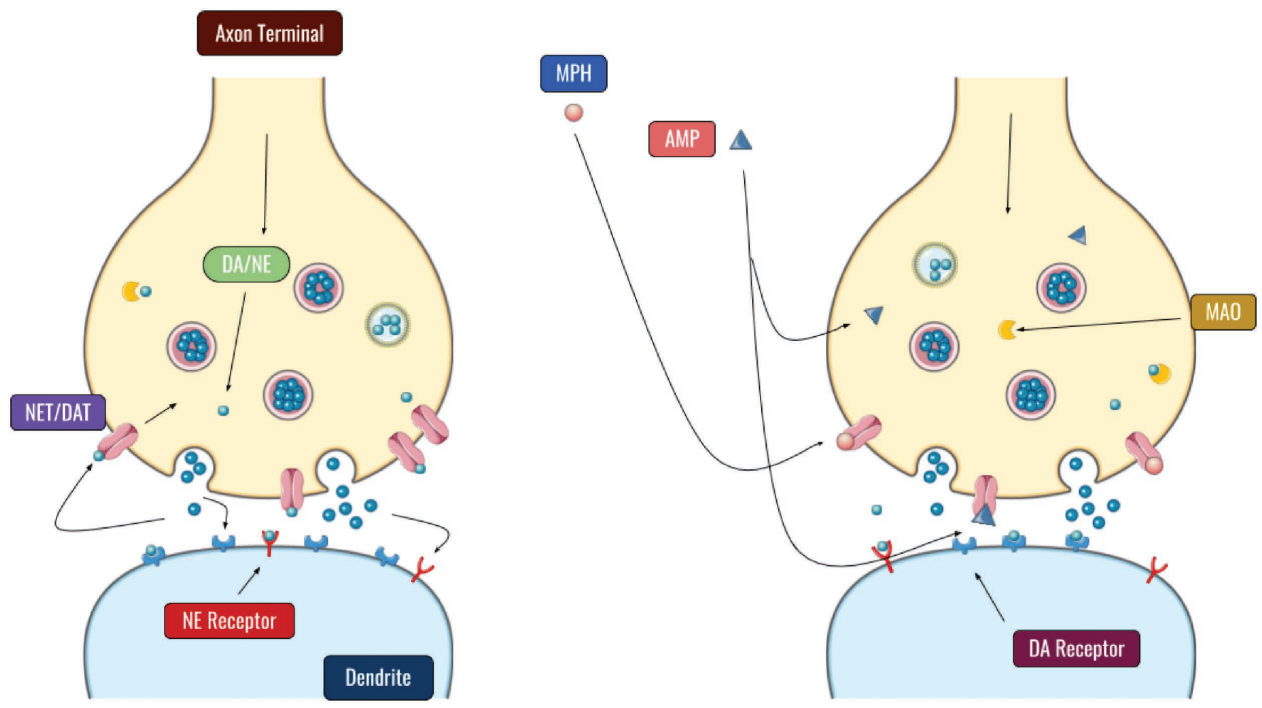

Figure 2. The schematic on the left depicts baseline DA and NE transmission. Much of the DA/NE undergoes reuptake into the presynaptic terminal, where it undergoes breakdown by monoamine oxidase (MAO), repackaging, or sequestration. The DA/NE that does make it into the synapse binds its respective receptor. AMP and MPH are the shown on the right. AMP can diffuse through the cell membrane, where it can bind MAO and transporters. It can also bind to DAT's, MPH, on the other hand, is a strong inhibitor of NET's.

synaptic availability of DA and NE. ${ }^{43,45,86}$ Interestingly, the mechanisms of action of AMP and MPH differ: MPH is a strong inhibitor of presynaptic dopamine transporters (DAT) and weak inhibitor of norepinephrine transporters, whereas AMP competitively inhibits DAT and norepinephrine transporters, increases DA release by inhibiting vesicular monoamine transporter 2, and blocks monoamine oxidase breakdown of DA and NE. ${ }^{43}$ The product of both drugs, though, is the aforementioned amplified concentration of stimulatory neurotransmitters in the synaptic cleft and availability for use. ${ }^{14}$ See Figure 2 for a simplified visual depiction of AMP and MPH mechanisms of action.

The therapeutic effect of AMP and MPH is dependent upon the rate of release, the dose, and the duration of activity of the formulation. ${ }^{14,87}$ This therapeutic effect has an inverted U-shape: up to a point, the increased DA and NE that results from stimulant medications normalizes PFC neuronal activity and dysfunctional executive functioning seen in ADHD, but excessive $\mathrm{DA}$ and NE results in neuronal death, impaired inhibitory signaling, and downstream behavioral consequences. ${ }^{88-90}$ Therapeutic formulations of MPH and AMP include extended-release and immediate-release and are designed to act along this U-shaped dose-response curve. Interestingly, the d-isomer of both AMP and MPH has more potent binding potential than the 1-isomer for their respective receptors of interest. ${ }^{87}$ Because $d$-AMP, the isoform most active in common pharmaceutical AMP, blocks reuptake of DA and increases DA and NE neuronal firing at therapeutic doses, ${ }^{43,87,91,92}$ clinicians should be aware of AMP's broad activity across the brain. ${ }^{14}$ This is especially true in those engaging in NMU, who commonly use supratherapeutic doses. ${ }^{85,93,94}$ Although meta-analyses have shown MPH and AMP to produce comparable benefits in executive functioning, the two have subtly different mechanisms of action. ${ }^{95,96}$ Like AMP, the $d$-isoform of MPH is the most active form, specifically binding PFC and striatal DAT in a dose-dependent relationship. ${ }^{97}$ This pharmacokinetic similarity explains the shared increases in extracellular DA and $\mathrm{NE}$ seen, although $\mathrm{MPH}$ also agonizes $5-\mathrm{HT}_{1 \mathrm{~A}} \cdot{ }^{43}$ Adrenergic 
receptors are activated, thus encouraging cortical excitability; guanfacine and clonidine, two non-stimulant medications used in ADHD management, have been shown to elicit similar effects. ${ }^{98} \mathrm{MPH}$, in a fashion analogous to cocaine but not AMP, does not act directly as a DA/ $\mathrm{NE}$ reuptake inhibitor; rather, $\mathrm{MPH}$ acts as an inverse agonist of DAT and NE transporters. ${ }^{99}$ Lastly, as mentioned previously, MPH inhibits DAT to a greater extent than AMP and thus indirectly increases dopaminergic and noradrenergic transmission. ${ }^{43,97}$

\section{Molecular and Clinical Manifestations of AMP/MPH Neurotoxicity}

\section{Molecular-AMP}

Most individuals engaging in NMU of AMP experience rapid sensitization. This is due to upregulation of DAT to accommodate unnatural synaptic DA concentrations, and therefore greater doses of AMP are required to achieve the sought-after euphoric effect with each subsequent dose. ${ }^{100}$ It is believed that behavioral reinforcement of euphoria, as well as sensitization (necessitating higher doses for effect), ${ }^{101}$ is regulated by the nucleus accumbens (NAcc), the region of the brain most associated with reward processing, pleasure sensation, and other behavioral processes associated with addiction. ${ }^{43}$ As dose increases beyond the therapeutic range, neurotoxic effects of greater DA concentrations begin to unfold in dopaminergic regions such as the NAcc, PFC, and the structures along the mesolimbic pathway. ${ }^{102}$ With chronic high-dose (ie, supratherapeutic) stimulant use comes alterations in dopamine receptors 2 and 3, presynaptic DA release and synthesis, and postsynaptic DAT availability, indicating a general attenuation of dopaminergic circuits. ${ }^{43,88,100,103}$ In animal models, this is hypothesized to be the result of neuronal death due to oxidative stress. ${ }^{104,105}$ In order to reach the euphoric effect many individuals seek by NMU, continued dose increases are necessary to break through tolerance, and, as the DA circuitry is already damaged, NMU escalation adds fuel to the fire. The rare psychoses reported among those who use stimulants appropriately, as well as the relatively common ones reported in non-medical users, are thought to arise from uncontrolled excitatory signaling resulting from aforementioned impairments in inhibitory signaling. ${ }^{88}$ It is hypothesized that to compensate for toxic DA concentrations, affected neurons decrease their DA receptor and transporter availability to prevent subsequent excitatory overstimulation. ${ }^{100}$ The downstream effect of this protective mechanism—diminished overall DA availability—results in neuropsychological dysfunction.

\section{Molecular-MPH}

Unlike AMP, MPH's effects on DA and NE are due also to disinhibition of dopamine receptor 2 and activation of dopamine receptor $1 .^{43} \mathrm{In}$ a murine model, chronic high-dose MPH exposure $(10 \mathrm{mg} / \mathrm{kg}$ daily for 12 weeks) has been associated with increased oxidative stress in nigrostriatal dopaminergic neurons, specifically due to heightened sensitivity to the toxin 1-methyl-4-phenyl-1,2,3,6-tetrahydropyridine (MPTP). ${ }^{106}$ MPTP is a strong substrate for the DA receptor and is tightly linked to the etiology and pathophysiology of Parkinson disease (PD). ${ }^{107}$ Oakes and colleagues at East Tennessee State University recently described a dose-dependent elevation in striatal dopaminergic neuronal DA-quinone production with chronic MPH exposure in a murine model. ${ }^{108}$ As the neuroimmune cascade is activated by oxidative stress, glutathione conjugates with the DA-quinone and sequesters it. Unfortunately, as glutathione reserves are depleted by chronic use, greater oxidative stress occurs. Although the majority of the literature regarding stimulant-induced neurotoxicity has focused on AMP, it is likely that the differential mechanisms of MPH-induced boosts in catecholamine concentration require specific 
investigation. This is salient given the differential effects of MPTP on dopaminergic neurons exposed to MPH compared to AMP. Whether MPH differs from AMP in its proclivity to actually induce Parkinsonism in individuals with ADHD or non-medical users has yet to be assessed. Clinicians should consider available evidence from animal and epidemiological studies of MPH-induced neuropathology when choosing appropriate treatment for ADHD, especially if the patient has a family history of PD.

\section{Clinical-AMP}

The most common clinical manifestations of AMP NMU-induced neurotoxicity include stroke, Parkinsonism, seizure, and psychosis. ${ }^{109}$ As the mechanism of action of methamphetamine is very similar to that of AMP, ${ }^{110}$ many of the potential adverse effects of methamphetamine use are liable in AMP NMU. The risk for hemorrhagic stroke, but not ischemic stroke, is increased between 5- and 7-fold among stimulant users under 45 years of age compared to those who do not use. ${ }^{109}$ Acute cerebrovascular effects (eg, hypertension, tachycardia, cerebral vasospasm) and chronic use-induced effects (eg, apoptosis of vascular smooth muscle, atherosclerosis, inflammatory vascular processes) of stimulants have been reported to put users at increased later risk for arrhythmias and resultant thromboembolism. ${ }^{109} \mathrm{PD}$ is thought to result from reduced striatal DA, DAT, and morphological defects in dopaminergic neurons. ${ }^{111}$ Given AMP NMU is observed to result in what are morphological precursors to $\mathrm{PD}$, the increased risk (1.5-3 times) and earlier onset (median of 6 years) of PD among those who use high-dose stimulants is understandable. ${ }^{109,112}$ The acutely augmented concentrations of DA associated with AMP NMU are also associated with lower concentrations of gamma-aminobutyric acid-the neurotransmitter involved in regulating excitatory and inhibitory signaling in the brain — and may lower seizure threshold. ${ }^{113}$

Finally, the occurrence of psychosis in those using AMP (2.4\%) and the high prevalence of AMP-induced episodic psychoses' conversion to schizophrenia ( 33\%) are clinically salient. ${ }^{114,115}$ Acute psychosis, though dynamic and complex, has long been associated with overactive DA signaling and transport. ${ }^{116}$ The pathophysiology of ADHD, as mentioned above, also involves dysregulation of DA. Granted, the correlation between DA and ADHD symptomatology is inverted in psychosis, but individual risk factors are not infrequently shared between psychiatric disorders. Supratherapeutic doses common to NMU are able to manifest psychotic symptoms, but the normalizing influence therapeutic AMP has on ADHD-associated DA signaling makes psychosis exceedingly rare in patients with ADHD. ${ }^{117}$ In the context of specifically AMPinduced psychosis, repeated use of high-dose stimulants in both therapeutic and misuse contexts is associated with greater blood-brain barrier porosity and tight-junction dysfunction. ${ }^{118}$ Interestingly, AMP is associated with a 4-fold greater DA release compared to MPH, which likely contributes to the greater probability of AMP- than MPH-induced psychosis. ${ }^{119}$ The treatment of both AMP-induced and organic psychoses involves dopamine receptor 2 blockade with antipsychotics with the intention to decrease overactive dopamine and associated transmission. ${ }^{115,116}$ Interestingly, many patients who benefit from DA blockade report adverse effects similar to ADHD symptoms: diminished subjective well-being, self-control, and cognitive functioning, as well as lethargy and emotional dysregulation. ${ }^{120,121}$

\section{Clinical-MPH}

$\mathrm{MPH}$ and AMP neurotoxicity is quite similar at the molecular level. This similarity can be mapped onto clinical outcomes, as well, with the important exception of psychosis. Moran 
and colleagues recently reported results from a large cohort study of individuals using MPH and AMP for ADHD. ${ }^{119}$ They found a 10-year incidence of 1.78 new psychotic episodes per 1000 person-years in those taking MPH compared to 2.83 new episodes per 1000 person-years in those taking AMP. The risk for stimulant-induced psychosis during the study period was also significantly attenuated in MPH-treated compared to AMP-treated patients $(0.10 \%$ and $0.21 \%$, respectively). ${ }^{119}$ Interestingly, there also appears to be a greater risk for psychosis in patients treated with AMP by physicians without psychiatric training when compared to those treated by board-certified psychiatrists. ${ }^{119}$ This highlights potential implications for the management of ADHD by primary care physicians and questions whether primary care should be the setting wherein ADHD is diagnosed, treated, and followed.

\section{Discussion}

The NMU of stimulants by healthy adults leads to mixed results at best and significant decreases in neuropsychological performance at worst. ${ }^{46,122-124}$ Much to the chagrin of healthy college students looking for a leg up, college grade point average and NMU are inversely correlated. ${ }^{71,123}$ Attention, inhibitory control, short-term episodic memory, and delayed episodic memory may be slightly positively affected by NMU, but cognitive functions such as working memory are worsened. ${ }^{122}$ Concerningly, students reporting their NMU in research settings fail to perceive that their use of stimulants carries risk of adverse effects or that NMU fails to produce positive changes that are worth the risk. It is therefore unlikely that deleterious neuropsychological and neurotoxic outcomes are being considered by those who engage in NMU. In contrast to NMU, the employment of prescription stimulants for ADHD is thought to be safe and effective for at least the short term. ${ }^{11}$ Upregulation of DAT, normalization of structural abnormalities, and increased striatal DA availability are associated with long-term treatment with MPH in individuals with ADHD. ${ }^{7,125}$ Working memory, response inhibition, and reaction time-domains commonly affected by ADHD—are reported to be positively impacted behavioral responses to the molecular and structural changes associated with treatment. ${ }^{7,126}$

The prevalence of prescription stimulant misuse in the adult population is deeply concerning at both the public health and clinical levels. This is compounded by the fact that the epidemiologic studies included in this review do not report a uniform estimated NMU prevalence. This may indicate a weak grasp by the public health community on the problem of stimulant NMU. Consideration of the stage of neurodevelopment that many adults reporting NMU are in, as well as the general dearth of literature considering long-term therapeutic use and NMU of prescription stimulants, will likely be of paramount importance to future clinicians treating ADHD and the potential negative sequelae of stimulant use. Future public health and clinical education should be augmented to include stimulant misuse trends and outcomes as practitioners in both arenas will likely encounter its effects as the population ages. ${ }^{127}$ As clinician societies and government agencies begin requiring drug manufacturers to consider long-term effectiveness in their stimulant medications, it is likely ADHD pharmacotherapy will evolve.

With the exception of just two large-scale studies-the Multimodal Treatment Study of Children With ADHD and the Comparison of Methylphenidate and Psychotherapy in Adult ADHD Study (COMPAS) - the consideration of pharmacotherapy's potential benefits and risks for patients long term remains wholly inadequate. ${ }^{128-130}$ For better or worse, current guidelines leave the formulation and dose of medication prescribed open to interpretation by clinicians. ${ }^{14}$ The precarious state of ADHD treatment was recently debated in the Journal of the American Academy of Child and Adolescent Psychiatry. ${ }^{131,132}$ Swanson, ${ }^{132}$ a University of California, 
Irvine professor of pediatrics and a principal investigator on the COMPAS, recently reported that the impressive effect sizes, symptom reduction, and behavioral outcomes associated with short-term pharmacotherapy have not conclusively been demonstrated to be maintained in the long term. In response to Swanson, Coghill, ${ }^{131}$ a renowned child/adolescent psychiatrist and scientist at the University of Melbourne, wrote that current trials continue to find that longterm pharmacotherapy is indeed effective when used dynamically, pragmatically, and subject to new clinical insights. Coghill's argument was reinforced by two studies recently published in the American Journal of Psychiatry: one finding sustained MPH effectiveness over 2 years in pediatric ADHD and the other finding inverse associations between long-term treatment and risk for suicide and substance abuse, among other outcomes. ${ }^{133,134}$

Parallel to substantive change to the ADHD management landscape, long-term, robust exploration of differences in outcomes between individuals who begin treatment in adulthood versus childhood, potential unknown neurological outcomes in the contexts of both NMU and $\mathrm{ADHD}$, and prescription stimulant toxicology is urgently needed. Questions related to long-term, consistent treatment with medication across the life span remain wide open to evidence-based and individualized study and conclusions, although the clinical recommendations in the $D S M^{-5}$ remain the gold standard given the current state of treatment options. Lastly, though this review of the literature is comprehensive, there are many basic unknowns concerning the relationship between prescription stimulants and neurotoxicity.

\section{Conclusion}

This narrative review presented the current understanding of prescription stimulant-induced neurotoxicity in both licit and illicit categories found in the literature. Although the sparse data available suggest long-term treatment of ADHD to be associated with positive outcomes in educational, social, psychological, and emotional domains, it is unclear whether this is due to the medications' continued action or the development of coping mechanisms over time. Additionally, as much the same for individuals engaged in NMU of MPH and AMP, future work is needed to measure the risks to and outcomes in neurological functioning and safety in those being treated for ADHD. It is also important to note that, though a comprehensive range of publications was considered for use in this review, the sheer number of records available made universal consideration impossible. Finally, beyond the clinical monitoring and treatment of potential sequelae, the public health and clinical communities must play a significantly more engaged role in educating the public about the proper use of stimulants-especially if we aim to prevent increased presentation of prescription stimulant neurotoxicity in the future.

\section{Acknowledgments}

I am deeply grateful for the scholarly guidance and encouragement of Dr. Justin A. Colacino, $\mathrm{PhD}, \mathrm{MA}, \mathrm{MPH}$ (University of Michigan School of Public Health). I also want to thank Dr. Sean E. McCabe, PhD (University of Michigan School of Nursing) for his inspiring intellectual and expert opinion, suggestions, and resourcefulness. I am thankful for the aid of Dr. Matthew S. Zawistowski, PhD (University of Michigan School of Public Health) in data manipulation. Finally, I want to thank Dr. Alfred Franzblau, MD (University of Michigan School of Public Health) for his mentorship. 


\section{Searches}

1. (((amphetamine OR methylphenidate)) AND (ADHD OR attention deficit hyperactivity disorder)) AND (treatment OR epidemiology OR adverse effects OR pathophysiology OR etiology) $-5576$

2. (((amphetamine OR methylphenidate)) AND (ADHD OR attention deficit hyperactivity disorder)) AND (treatment OR epidemiology OR adverse effects OR pathophysiology OR etiology) AND (English[lang]) - 5228

3. (((amphetamine OR methylphenidate)) AND (ADHD OR attention deficit hyperactivity disorder)) AND (treatment OR epidemiology OR adverse effects OR pathophysiology OR etiology) AND ((Journal Article[ptyp] OR Review[ptyp]) AND English[lang]) - 4851

4. (((() amphetamine or methylphenidate)) AND (ADHD or attention deficit hyperactivity disorder)) AND (treatment or epidemiology or adverse effects or pathophysiology or etiology)) AND ((Journal Article[ptyp] OR Review[ptyp]) AND English[lang])) AND (Journal Article[ptyp] OR Review[ptyp]) AND (“2005/01/01”[PDat]: “3000/12/31”[PDat]) AND English[lang $-3397$

5. (((((amphetamine or methylphenidate)) AND (ADHD or attention deficit hyperactivity disorder)) AND (treatment or epidemiology or adverse effects or pathophysiology or etiology)) AND ((Journal Article[ptyp] OR Review[ptyp]) AND English[lang])) AND (Journal Article[ptyp] OR Review[ptyp]) AND (“2005/01/01”[PDat]: “3000/12/31”[PDat]) AND English[lang] AND (Journal Article[ptyp] OR Review[ptyp]) AND hasabstract[text] AND (“2005/01/01”[PDat]: “3000/12/31”[PDat]) AND English[lang] - 3256

6. (((((amphetamine or methylphenidate)) AND (ADHD or attention deficit hyperactivity disorder)) AND (treatment or epidemiology or adverse effects or pathophysiology or etiology)) AND ((Journal Article[ptyp] OR Review[ptyp]) AND English[lang])) AND (Journal Article[ptyp] OR Review[ptyp]) AND (“2005/01/01”[PDat]: “3000/12/31”[PDat]) AND English[lang] AND (Journal Article[ptyp] OR Review[ptyp]) AND hasabstract[text] AND (“2005/01/01”[PDat]: “3000/12/31”[PDat]) AND English[lang] AND (jsubsetaim[text] OR medline[sb]) - 2879

7. $\quad((((((($ amphetamine or methylphenidate $))$ AND (ADHD or attention deficit hyperactivity disorder)) AND (treatment or epidemiology or adverse effects or pathophysiology or etiology)) AND ((Journal Article[ptyp] OR Review[ptyp]) AND English[lang])) AND (Journal Article[ptyp] OR Review[ptyp]) AND (“2005/01/01”[PDat]: “3000/12/31”[PDat]) AND English[lang]) AND ((Journal Article[ptyp] OR Review[ptyp]) AND hasabstract[text] AND (“2005/01/01”[PDat]: “3000/12/31”[PDat]) AND English[lang] AND (jsubsetaim[text] OR medline[sb])))) NOT (infant or trauma or driving or pregnancy or comorbid or autism or natural or adjunct or complementary or supplement or mineral or herbal or vitamin or intellectual or disability) AND (Journal Article[ptyp] OR Review[ptyp]) AND hasabstract[text] AND (“2005/01/01”[PDat]: “3000/12/31”[PDat]) AND English[lang] AND (jsubsetaim[text] OR medline[sb]) - 2047

8. Search $((((()($ amphetamine or methylphenidate) $))$ AND (ADHD or attention deficit hyperactivity disorder)) AND (treatment or epidemiology or adverse effects or pathophysiology or etiology)) AND ((Journal Article[ptyp] OR Review[ptyp]) AND English[lang])) AND (Journal Article[ptyp] OR Review[ptyp]) AND (“2005/01/01”[PDat]: “3000/12/31”[PDat]) AND English[lang]) AND ((Journal Article[ptyp] OR Review[ptyp]) AND hasabstract[text] AND (“2005/01/01”[PDat]: “3000/12/31”[PDat]) AND English[lang] AND (jsubsetaim[text] OR medline[sb])))) NOT (infant or trauma or driving or pregnancy or comorbid or autism or natural or adjunct or complementary or supplement or mineral or herbal or vitamin or intellectual or disability) Sort by: Best Match Filters: Journal Article; Review; Full text; Publication date from 2005/01/01; English; Core clinical journals; MEDLINE - 1992 
1. (((amphetamine or methylphenidate or central nervous system stimulant)) AND (toxicology or pharmacology or abuse or misuse)) - 96359

2. (((amphetamine or methylphenidate or central nervous system stimulant)) AND (toxicology or pharmacology or abuse or misuse)) AND English[lang] - 87275

3. (((amphetamine or methylphenidate or central nervous system stimulant)) AND (toxicology or pharmacology or abuse or misuse)) AND (Journal Article[ptyp] OR Review[ptyp]) AND English[lang] - 84789

4. (((amphetamine or methylphenidate or central nervous system stimulant)) AND (toxicology or pharmacology or abuse or misuse)) AND (Journal Article[ptyp] OR Review[ptyp]) AND (“2005/01/01”[PDat]: “3000/12/31”[PDat]) AND English[lang] - 31575

5. (((amphetamine or methylphenidate or central nervous system stimulant)) AND (toxicology or pharmacology or abuse or misuse)) AND (Journal Article[ptyp] OR Review[ptyp]) AND hasabstract[text] AND (“2005/01/01”[PDat]: “3000/12/31”[PDat]) AND English[lang] - 30749

6. (((amphetamine or methylphenidate or central nervous system stimulant)) AND (toxicology or pharmacology or abuse or misuse)) AND (Journal Article[ptyp] OR Review[ptyp]) AND hasabstract[text] AND (“2005/01/01”[PDat]: “3000/12/31”[PDat]) AND English[lang] AND (jsubsetaim[text] OR medline[sb]) - 30117

7. ((((() amphetamine or methylphenidate or central nervous system stimulant)) AND (toxicology or pharmacology or abuse or misuse))) AND ((Journal Article[ptyp] OR Review[ptyp]) AND hasabstract[text] AND (“2005/01/01”[PDat]: “3000/12/31”[PDat]) AND English[lang] AND (jsubsetaim[text] OR medline[sb])))) NOT (infant or trauma or driving or pregnancy or comorbid or autism or natural or adjunct or complementary or supplement or mineral or herbal or vitamin or intellectual or disability) AND (Journal Article[ptyp] OR Review[ptyp]) AND hasabstract[text] AND (“2005/01/01”[PDat]: “3000/12/31”[PDat]) AND English[lang] AND (jsubsetaim[text] OR medline[sb]) - 23279

Search $((((((($ amphetamine or methylphenidate or central nervous system stimulant $))$ AND (toxicology or pharmacology or abuse or misuse))) AND ((Journal Article[ptyp] OR Review[ptyp]) AND hasabstract[text] AND (“2005/01/01”[PDat]: “3000/12/31”[PDat]) AND English[lang] AND (jsubsetaim[text] OR medline[sb])))) NOT (infant or trauma or driving or pregnancy or comorbid or autism or natural or adjunct or complementary or supplement or mineral or herbal or vitamin or intellectual or disability)) AND ((Journal Article[ptyp] OR Review[ptyp]) AND hasabstract[text] AND (“2005/01/01”[PDat]: “3000/12/31”[PDat]) AND English[lang] AND (jsubsetaim[text] OR medline[sb]))) Sort by: Best Match Filters: Journal Article; Review; Full text; Publication date from 2005/01/01; English; Core clinical journals; MEDLINE - 22750

\section{References}

1. Heal DJ, Smith SL, Gosden J, Nutt DJ. Amphetamine, past and present-a pharmacological and clinical perspective. J Psychopharmacol. 2013;27(6):479-496. doi:10.1177/0269881113482532

2. Gallo EF, Posner J. Moving towards causality in attention-deficit hyperactivity disorder: overview of neural and genetic mechanisms. Lancet Psychiatry. 2016;3(6):555-567. doi:10.1016/ S2215-0366(16)00096-1

3. Bellani M, Moretti A, Perlini C, Brambilla P. Language disturbances in ADHD. Epidemiol Psychiatr Sci.2011;20(4):311-315. doi:10.1017/S2045796011000527

4. American Psychiatric Association. DSM-5 diagnostic classification. In: Diagnostic and Statistical Manual of Mental Disorders. 5th ed. American Psychiatric Association; 2013. doi:10.1176/appi. books.9780890425596.x00diagnosticclassification

5. Wolraich ML, Hagan JF, Allan C, et al. Clinical practice guideline for the diagnosis, evaluation, and treatment of attention-deficit/hyperactivity disorder in children and adolescents. Pediatrics. 2019;144(4):e20192528. doi:10.1542/peds.2019-2528 
6. Volkow ND, Swanson JM. Clinical practice: adult attention deficit-hyperactivity disorder. N Engl JMed.2013;369(20):1935-1944. doi:10.1056/NEJMcp1212625

7. Mahone EM, Denckla MB. Attention-deficit/hyperactivity disorder: a historical neuropsychological perspective. J Int Neuropsychol Soc. 2017;23(9-10 special issue):916-929. doi:10.1017/ S1355617717000807

8. Posner J, Polanczyk GV, Sonuga-Barke E. Attention-deficit hyperactivity disorder. Lancet. 2020;395(10222):450-462. doi:10.1016/S0140-6736(19)33004-1

9. Uchida M, Spencer TJ, Faraone SV, Biederman J. Adult outcome of ADHD: an overview of results from the MGH longitudinal family studies of pediatrically and psychiatrically referred youth with and without ADHD of both sexes. J Atten Disord. 2018;22(6):523-534. doi:10.1177/1087054715604360

10. Chan E, Fogler JM, Hammerness PG. Treatment of attention-deficit/hyperactivity disorder in adolescents: a systematic review. JAMA. 2016;315(18):1997-2008. doi:10.1001/jama.2016.5453

11. Young JL, Goodman DW. Adult attention-deficit/hyperactivity disorder diagnosis, management, and treatment in the DSM-5 era. Prim Care Companion CNS Discord. 2016;18(6). doi:10.4088/ PCC.16r02000

12. Mattingly GW, Wilson J, Rostain AL. A clinician's guide to ADHD treatment options. Postgrad Med. 2017;129(7):657-666. doi:10.1080/00325481.2017.1354648

13. Briars L, Todd T. A review of pharmacological management of attention-deficit/hyperactivity disorder.J Pediatr Pharmacol Ther. 2016;21(3):192-206. doi:10.5863/1551-6776-21.3.192

14. Childress AC, Komolova M, Sallee FR. An update on the pharmacokinetic considerations in the treatment of ADHD with long-acting methylphenidate and amphetamine formulations. Expert Opin Drug Metab Toxicol. 2019;15(11):937-974. doi:10.1080/17425255.2019.1675636

15. Rasmussen N. Amphetamine-type stimulants: the early history of their medical and non-medical uses. Int Rev Neurobiol. 2015;120:9-15. doi:10.1016/bs.irn.2015.02.001

16. Xu G, Strathearn L, Liu B, Yang B, Bao W. Twenty-year trends in diagnosed attention-deficit/hyperactivity disorder among US children and adolescents, 1997-2016. JAMA Netw Open. 2018;1(4):e181471. doi:10.1001/jamanetworkopen.2018.1471

17. Thapar A, Cooper M. Attention deficit hyperactivity disorder. Lancet. 2015;387(10024):12401250. doi:10.1016/S0140-6736(15)00238-X

18. Faraone SV, Rostain AL, Montano CB, Mason O, Antshel KM, Newcorn JH. Systematic review: nonmedical use of prescription stimulants: risk factors, outcomes, and risk reduction strategies.

J Am Acad Child Adolesc Psychiatry. 2020;59(1):100-112. doi:10.1016/j.jaac.2019.06.012

19. Compton WM, Han B, Blanco C, Johnson K, Jones CM. Prevalence and correlates of prescription stimulant use, misuse, use disorders, and motivations for misuse among adults in the United States. Am J Psychiatry. 2018;175(8):741-755. doi:10.1176/appi.ajp.2018.17091048

20. Wolraich ML, Chan E, Froehlich T, et al. ADHD diagnosis and treatment guidelines: a historical perspective. Pediatrics. 2019;144(4):e20191682. doi:10.1542/peds.2019-1682

21. McCabe SE, Veliz P, Wilens TE, Schulenberg JE. Adolescents' prescription stimulant use and adult functional outcomes: a national prospective study. J Am Acad Child Adolesc Psychiatry. 2017;56(3):226-233.e4. doi:10.1016/j.jaac.2016.12.008

22. American Psychiatric Association. Diagnostic and Statistical Manual of Mental Disorders. 3rd ed. American Psychiatric Association; 1980.

23. Wilens TE, Biederman J, Faraone SV, Martelon M, Westerberg D, Spencer TJ. Presenting ADHD symptoms, subtypes, and comorbid disorders in clinically referred adults with ADHD. J Clin Psychiatry. 2009;70(11):1557-1562. doi:10.4088/JCP.08m04785pur

24. Bonvicini C, Faraone SV, Scassellati C. Attention-deficit hyperactivity disorder in adults: a systematic review and meta-analysis of genetic, pharmacogenetic and biochemical studies. Mol Psychiatry. 2016;21(7):872-884. doi:10.1038/mp.2016.74

25. Demontis D, Walters RK, Martin J, et al. Discovery of the first genome-wide significant risk loci for attention deficit/hyperactivity disorder. Nat Genet.2019;51(1):63-75. doi:10.1038/ s41588-018-0269-7 
26. Faraone SV, Asherson P, Banaschewski T, et al. Attention-deficit/hyperactivity disorder. Nat Rev Dis Primers. 2015;1:15020. doi:10.1038/nrdp.2015.20

27. Sharma A, Couture J. A review of the pathophysiology, etiology, and treatment of attention-deficit hyperactivity disorder (ADHD). Ann Pharmacother. 2014;48(2):209-225. doi:10.1177/1060028013510699

28. Mereu M, Contarini G, Buonaguro EF, et al. Dopamine transporter (DAT) genetic hypofunction in mice produces alterations consistent with ADHD but not schizophrenia or bipolar disorder. Neuropharmacology. 2017;121:179-194. doi:10.1016/j.neuropharm.2017.04.037

29. Franke B, Faraone SV, Asherson P, et al. The genetics of attention deficit/hyperactivity disorder in adults, a review. Mol Psychiatry. 2012;17:960-987. doi:10.1038/mp.2011.138

30. Faraone SV, Larsson H. Genetics of attention deficit hyperactivity disorder. Mol Psychiatry. 2019;24:562-575. doi:10.1038/s41380-018-0070-0

31. Montarolo F, Martire S, Perga S, et al. NURR1 deficiency is associated to ADHD-like phenotypes in mice. Transl Psychiatry. 2019;9(1):207. doi:10.1038/s41398-019-0544-0

32. Spencer RC, Devilbiss DM, Berridge CW. The cognition-enhancing effects of psychostimulants involve direct action in the prefrontal cortex. Biol Psychiatry. 2015;77(11):940-950. doi:10.1016/j. biopsych.2014.09.013

33. Arnsten AFT, Pliszka SR. Catecholamine influences on prefrontal cortical function: relevance to treatment of attention deficit/hyperactivity disorder and related disorders. Pharmacol Biochem Bebav. 2011;99(2):211-216. doi:10.1016/j.pbb.2011.01.020

34. Di Miceli M, Gronier B. Psychostimulants and atomoxetine alter the electrophysiological activity of prefrontal cortex neurons, interaction with catecholamine and glutamate NMDA receptors. Psychopharmacology (Berl). 2015;232(12):2191-2205. doi:10.1007/s00213-014-3849-y

35. Aggarwal S, Mortensen OV. Overview of monoamine transporters. Curr Protoc Pharmacol. 2017;7912.16.1-12.16.17. doi:10.1002/cpph.32

36. Wilens TE. Mechanism of action of agents used in attention-deficit/hyperactivity disorder. J Clin Psychiatry. 2006;67(suppl 8):32-38.

37. Vaughan RA, Foster JD. Mechanisms of dopamine transporter regulation in normal and disease states. Trends Pharmacol Sci.2013;34(9):489-496. doi:10.1016/j.tips.2013.07.005

38. Devilbiss DM, Berridge CW. Cognition-enhancing doses of methylphenidate preferentially increase prefrontal cortex neuronal responsiveness. Biol Psychiatry. 2008;64(7):626-635. doi:10.1016/j.biopsych.2008.04.037

39. Xing B, Li Y-C, Gao W-J. Norepinephrine versus dopamine and their interaction in modulating synaptic function in the prefrontal cortex. Brain Res. 2016;1641(pt B):217-233. doi:10.1016/j. brainres.2016.01.005

40. Spencer RC, Klein RM, Berridge CW. Psychostimulants act within the prefrontal cortex to improve cognitive function. Biol Psychiatry. 2012;72(3):221-227. doi:10.1016/j.biopsych. 2011.12.002

41. Schmeichel BE, Berridge CW. Neurocircuitry underlying the preferential sensitivity of prefrontal catecholamines to low-dose psychostimulants. Neuropsychopharmacology. 2013;38(6):1078-1084. doi:10.1038/npp.2013.6

42. Weyandt LL, Marraccini ME, Gudmundsdottir BG, et al. Misuse of prescription stimulants among college students: a review of the literature and implications for morphological and cognitive effects on brain functioning. Exp Clin Psychopharmacol. 2013;21(5):385-407. doi:10.1037/ a0034013

43. Faraone SV. The pharmacology of amphetamine and methylphenidate: relevance to the neurobiology of attention-deficit/hyperactivity disorder and other psychiatric comorbidities. Neurosci Biobehav Rev. 2018;87:255-270. doi:10.1016/j.neubiorev.2018.02.001

44. Cheng J, Liu A, Shi MY, Yan Z. Disrupted glutamatergic transmission in prefrontal cortex contributes to behavioral abnormality in an animal model of ADHD. Neuropsychopharmacology. 2017;42(10):2096-2104. doi:10.1038/npp.2017.30 
45. Brown KA, Samuel S, Patel DR. Pharmacologic management of attention deficit hyperactivity disorder in children and adolescents: a review for practitioners. Transl Pediatr. 2018;7(1):36-47. doi:10.21037/tp.2017.08.02

46. Wilens TE, Carrellas NW, Martelon MK, et al. Neuropsychological functioning in college students who misuse prescription stimulants. Am J Addict.2017;26(4):379-387. doi:10.1111/ajad.12551

47. Kessler RC, Adler L, Ames M, et al. The World Health Organization Adult ADHD SelfReport Scale (ASRS): a short screening scale for use in the general population. Psychol Med. 2005;35(2):245-256. doi:10.1017/S0033291704002892

48. National Collaborating Centre for Methods and Tools. Quality assessment tool for quantitative studies. Effective Public Health Practice Project. McMaster University, Toronto.

49. Young JG. Methylphenidate-induced hallucinosis: case histories and possible mechanisms of action.J Dev Behav Pediatr. 1981;2(2):35-38. doi:10.1097/00004703-198106000-00003

50. Moher D, Liberati A, Tetzlaff J, Altman DG, PRISMA Group. Preferred reporting items for systematic reviews and meta-analyses: the PRISMA statement. PLoS Med.2009;6(7):e1000097. doi:10.1371/journal.pmed.1000097

51. Lakhan SE, Kirchgessner A. Prescription stimulants in individuals with and without attention deficit hyperactivity disorder: misuse, cognitive impact, and adverse effects. Brain Behav. 2012;2(5):661-677. doi:10.1002/brb3.78

52. DeSantis A, Noar SM, Webb EM. Speeding through the frat house: a qualitative exploration of nonmedical ADHD stimulant use in fraternities.J Drug Educ. 2010. doi:10.2190/DE.40.2.d

53. Wilens TE, Kaminski TA. Prescription stimulants: from cognitive enhancement to misuse. Pediatr Clin North Am. 2019;66(6):1109-1120. doi:10.1016/j.pcl.2019.08.006

54. Robitaille $\mathrm{C}$, Collin J. Prescription psychostimulant use among young adults: a narrative review of qualitative studies. Subst Use Misuse. 2016;51(3):357-369. doi:10.3109/10826084.2015.1110170

55. Grant BF, Saha TD, Ruan WJ, et al. Epidemiology of DSM-5 drug use disorder: results from the national epidemiologic survey on alcohol and related conditions-III. JAMA Psychiatry. 2016;73(1):39-47. doi:10.1001/jamapsychiatry.2015.2132

56. Arain M, Haque M, Johal L, et al. Maturation of the adolescent brain. Neuropsychiatr Dis Treat. 2013;9:449-461. doi:10.2147/NDT.S39776

57. Mui HZ, Sales P, Murphy S. Everybody's doing it: initiation to prescription drug misuse. J Drug Issues. 2014;44(3):236-253. doi:10.1177/0022042613497935

58. Phillips EL, McDaniel AE. College Prescription Drug Study Key Findings Report. The Ohio State University; 2018.

59. Substance Abuse and Mental Health Services Administration. Key Substance Use and Mental Health Indicators in the United States: Results from the 2018 National Survey on Drug Use and Health. US Department of Health and Human Services; 2019.

60. Upadhyaya HP, Kroutil LA, Deas D, Durell TM, Van Brunt DL, Novak SP. Stimulant formulation and motivation for nonmedical use of prescription attention-deficit/hyperactivity disorder medications in a college-aged population. Am J Addict. 2010;19(6):569-577. doi:10.1111/j.1521-0391.2010.00078.x

61. Quinn PD, Chang Z, Hur K, et al. ADHD medication and substance-related problems. Am J Psychiatry. 2017;174(9):877-885. doi:10.1176/appi.ajp.2017.16060686

62. Upadhyay N, Chen H, Mgbere O, Bhatara VS, Aparasu RR. The impact of pharmacotherapy on substance use in adolescents with attention-deficit/hyperactivity disorder: variations across subtypes. Subst Use Misuse. 2017;52(10):1266-1274. doi:10.1080/10826084.2016.1273955

63. Asherson P. Drug treatments for ADHD reduce risk of substance use disorders. Am J Psychiatry. 2017;174(9):827-828. doi:10.1176/appi.ajp.2017.17070733

64. Teter CJ, Esteban S, Cranford JA, et al. Prevalence and motives for illicit use of prescription stimulants in an undergraduate student sample. J Am Coll Health. 2005. doi:10.3200/ JACH.53.6.253-262 
65. Teter CJ, McCabe SE, LaGrange K, et al. Illicit use of specific prescription stimulants among college students: Prevalence, motives, and routes of administration. Pharmacotherapy. 2006. doi:10.1592/phco.26.10.1501

66. Lord S, Downs G, Furtaw P, et al. Nonmedical use of prescription opioids and stimulants among student pharmacists.J Am Pharm Assoc. 2009. doi:10.1331/JAPhA.2009.08027

67. Weyandt LL, Janusis G, Wilson KG, et al. Nonmedical prescription stimulant use among a sample of college students: Relationship with psychological variables.J Atten Disord. 2009. doi:10.1177/1087054709342212

68. Rabiner DL, Anastopoulos AD, Costello EJ, et al. Predictors of nonmedical ADHD medication use by college students. J Atten Disord. 2010;13(6):640-648. doi:10.1177/1087054709334505

69. Clegg-Kraynok MM, McBean AL, Montgomery-Downs HE. Sleep quality and characteristics of college students who use prescription psychostimulants nonmedically. Sleep Med. 2011;12(6):598-602.

70. Garnier-Dykstra LM, Caldeira KM, Vincent KB, et al. Nonmedical use of prescription stimulants during college: four-year trends in exposure opportunity, use, motives, and sources. J Am Coll Health. 2012;60(3):226-234. doi:10.1080/07448481.2011.589876

71. Lookatch SJ, Dunne EM, Katz EC. Predictors of nonmedical use of prescription stimulants. J Psychoact Drugs. 2012. doi:10.1080/02791072.2012.662083

72. Bavarian N, Flay BR, Ketcham PL, et al. Illicit use of prescription stimulants in a college student sample: A theory-guided analysis. Drug Alcohol Depend. 2013. doi:10.1016/j. drugalcdep.2013.04.024

73. Hartung CM, Canu WH, Cleveland CS, et al. Stimulant medication use in college students: Comparison of appropriate users, misusers, and nonusers. Psychol Addict Behav. 2013. doi:10.1037/a0033822

74. Wasserman JA, Fitzgerald JE, Sunny MA, et al. Nonmedical use of stimulants among medical students.J Osteopathic Med.2014;114(8). https://doi.org/10.7556/jaoa.2014.129

75. Messina BG, Silvestri MM, Diulio AR, et al. Alcohol use, impulsivity, and the non-medical use of prescription stimulants among college students. Addict Behav. 2014;39(12). https://doi. org/10.1016/j.addbeh.2014.07.012

76. Meisel MK, Goodie AS. Predicting prescription drug misuse in college students' social networks. Addict Behav. 2015;45. https://doi.org/10.1016/j.addbeh.2015.01.025

77. Cassidy TA, Varughese S, Russo L, et al. Nonmedical use and diversion of ADHD stimulants among U.S. adults ages 18-49. J Atten Disord. 2015;19(7). https://doi. org $/ 10.1177 / 1087054712468486$

78. Gallucci AR, Usdan SL, Martin RJ, et al. Pill popping problems: The non-medical use of stimulant medications in an undergraduate sample. Drugs Educ Prev Policy. 2014.

79. Weyandt LL, Oster DR, Marraccini ME, et al. Prescription stimulant medication misuse: Where are we and where do we go from here? Exp Clin Psychopharmacol. 2016. doi:10.1037/ pha0000093

80. Bavarian N, McMullen J, Flay BR, et al. A mixed-methods approach examining illicit prescription stimulant use: Findings from a northern California University. J Prim Prevent. 2017;38(4). https://doi.org/10.1007/s10935-017-0465-8

81. Kinman BA, Armstrong KJ, Hood KB. Perceptions of risks and benefits among nonprescription stimulant consumers, diverters, and non-users. Subst Use Misuse. 2017;52(10). https://doi.org/10.1 080/10826084.2016.1273954

82. Schepis TS, Teter CJ, McCabe SE. Prescription drug use, misuse and related substance use disorder symptoms vary by educational status and attainment in U.S. adolescents and young adults. Drug Alcohol Depend. 2018;189. https://doi.org/10.1016/j.drugalcdep.2018.05.017

83. Le VT, Norris Turner A, McDaniel A, et al. Nonmedical use of over-the-counter medications is significantly associated with nonmedical use of prescription drugs among university students. J Am Coll Health. 2018;66(1). https://doi.org/10.1080/07448481.2017.1356312 
84. Schulenberg J, Johnston L, O'Malley P, et al. Monitoring the Future National Survey Results on Drug Use, 1975-2018: Volume II, College Students and Adults Ages; 2019:19-60.

85. Rabiner DL, Anastopoulos AD, Costello EJ, Hoyle RH, McCabe SE, Swartzwelder HS. The misuse and diversion of prescribed ADHD medications by college students. J Atten Disord. 2009;13(2):144-153. doi:10.1177/1087054708320414

86. Soto PL, Wilcox KM, Zhou Y, et al. Erratum: long-term exposure to oral methylphenidate or dl-amphetamine mixture in peri-adolescent rhesus monkeys: effects on physiology, behavior, and dopamine system development. Neuropsychopharmacology. 2013;38(6):1141. doi:10.1038/npp.2013.15

87. Markowitz JS, Patrick KS. The clinical pharmacokinetics of amphetamines utilized in the treatment of attention-deficit/hyperactivity disorder.J Child Adolesc Psychopharmacol. 2017;27(8): 678-689. doi:10.1089/cap.2017.0071

88. Gonçalves J, Baptista S, Silva AP. Psychostimulants and brain dysfunction: a review of the relevant neurotoxic effects. Neuropharmacology. 2014;87:135-149. doi:10.1016/j. neuropharm.2014.01.006

89. Weyandt LL, Oster DR, Marraccini ME, et al. Prescription stimulant medication misuse: where are we and where do we go from here? Exp Clin Psychopharmacol.2016;24(5):400-414. doi:10.1037/pha0000093

90. Arnsten AFT. Stimulants: therapeutic actions in ADHD. Neuropsychopharmacology. 2006;31(11):2376-2383. doi:10.1038/sj.npp.1301164

91. Courtney KE, Ray LA. Clinical neuroscience of amphetamine-type stimulants: from basic science to treatment development. Prog Brain Res. 2016;223:295-310. doi:10.1016/ bs.pbr.2015.07.010

92. Reith MEA, Gnegy ME. Molecular mechanisms of amphetamines. Handb Exp Pharmacol. 2020;258:265-297.doi:10.1007/164_2019_251

93. Steiner $\mathrm{H}$, Van Waes V. Addiction-related gene regulation: risks of exposure to cognitive enhancers vs. other psychostimulants. Prog Neurobiol. 2013;100(1):60-80. doi:10.1016/j. pneurobio.2012.10.001

94. Urban KR, Gao W-J. Psychostimulants as cognitive enhancers in adolescents: more risk than reward? Front Public Health. 2017;5:260. doi:10.3389/fpubh.2017.00260

95. Catalá-López F, Hutton B, Núñez-Beltrán A, et al. The pharmacological and non-pharmacological treatment of attention deficit hyperactivity disorder in children and adolescents: protocol for a systematic review and network meta-analysis of randomized controlled trials. Syst Rev. 2015;4:19. doi:10.1186/s13643-015-0005-7

96. Faraone SV, Glatt SJ. A comparison of the efficacy of medications for adult attention-deficit/ hyperactivity disorder using meta-analysis of effect sizes. J Clin Psychiatry. 2010;71(6):754-763. doi:10.4088/JCP.08m04902pur

97. Wilens TE. Effects of methylphenidate on the catecholaminergic system in attention-deficit/hyperactivity disorder. J Clin Psychopharmacol. 2008;28(3 suppl 2):S46-S53. doi:10.1097/ JCP.0b013e318173312f

98. Jain R, Katic A. Current and investigational medication delivery systems for treating attention-deficit/hyperactivity disorder. Prim Care Companion CNS Disord. 2016;18(4). doi:10.4088/ PCC.16r01979

99. Heal DJ, Gosden J, Smith SL. Dopamine reuptake transporter (DAT) “inverse agonism”-a novel hypothesis to explain the enigmatic pharmacology of cocaine. Neuropharmacology. 2014;87:19-40. doi:10.1016/j.neuropharm.2014.06.012

100. Schrantee A, Václavů L, Heijtel DFR, et al. Dopaminergic system dysfunction in recreational dexamphetamine users. Neuropsychopharmacology. 2015;40(5):1172-1180. doi:10.1038/ npp.2014.301

101. Wang Q, Li D, Bubula N, Campioni MR, McGehee DS, Vezina P. Sensitizing exposure to amphetamine increases AMPA receptor phosphorylation without increasing cell surface expression in the rat nucleus accumbens. Neuropharmacology. 2017;117:328-337. doi:10.1016/ j.neuropharm.2017.02.018 
102. Berman SM, Kuczenski R, McCracken JT, London ED. Potential adverse effects of amphetamine treatment on brain and behavior: a review. Mol Psychiatry. 2009;14(2):123-142. doi:10.1038/mp.2008.90

103. Ashok AH, Mizuno Y, Volkow ND, Howes OD. Association of stimulant use with dopaminergic alterations in users of cocaine, amphetamine, or methamphetamine: a systematic review and meta-analysis. JAMA Psychiatry. 2017;74(5):511-519. doi:10.1001/jamapsychiatry.2017.0135

104. Lohr KM, Masoud ST, Salahpour A, Miller GW. Membrane transporters as mediators of synaptic dopamine dynamics: implications for disease. Eur J Neurosci.2017;45(1):20-33. doi:10.1111/ ejn. 13357

105. Cadet JL, Krasnova IN, Jayanthi S, Lyles J. Neurotoxicity of substituted amphetamines: molecular and cellular mechanisms. Neurotox Res. 2007;11(3-4):183-202. doi:10.1007/BF03033567

106. Sadasivan S, Pond BB, Pani AK, Qu C, Jiao Y, Smeyne RJ. Methylphenidate exposure induces dopamine neuron loss and activation of microglia in the basal ganglia of mice. PLoS One. 2012;7(5). doi:10.1371/journal.pone.0033693

107. Langston JW. The MPTP story. J Parkinsons Dis. 2017;7(suppl 1):S11-S19. doi:10.3233/ JPD-179006

108. Oakes HV, Ketchem S, Hall AN, Ensley T, Archibald KM, Pond BB. Chronic methylphenidate induces increased quinone production and subsequent depletion of the antioxidant glutathione in the striatum. Pharmacol Reports. 2019;71(6):1289-1292. doi:10.1016/j.pharep.2019.08.003

109. Lappin JM, Sara GE. Psychostimulant use and the brain. Addiction. 2019;114(11):2065-2077. doi:10.1111/add.14708

110. Nestler EJ, Hyman SE, Malenka RC. Molecular Neuropharmacology: A Foundation for Clinical Neuroscience. 2nd ed. McGraw-Hill; 2009.

111. Kalia LV, Lang AE. Parkinson's disease. Lancet. 2015;386(9996):896-912. doi:10.1016/ S0140-6736(14)61393-3

112. Dowling GJ, Weiss SRB, Condon TP. Drugs of abuse and the aging brain. Neuropsychopharmacology. 2008;33:209-218. doi:10.1038/sj.npp.1301412

113. Childress A. The safety of extended-release drug formulations for the treatment of ADHD. Expert Opin Drug Saf. 2017;16(5):603-615. doi:10.1080/14740338.2017.1317344

114. Medhus S, Rognli EB, Gossop M, Holm B, Mørland J, Bramness JG. Amphetamine-induced psychosis: transition to schizophrenia and mortality in a small prospective sample. Am J Addict. 2015;24(7):586-589. doi:10.1111/ajad.12274

115. Lieberman JA, First MB. Psychotic disorders. N EnglJ Med.2018;379(3):270-280. doi:10.1056/ NEJMra1801490

116. Marder SR, Cannon TD. Schizophrenia. N Engl J Med.2019;381(18):1753-1761. doi:10.1056/ NEJMra1808803

117. Voce A, McKetin R, Burns R, Castle D, Calabria B. The relationship between illicit amphetamine use and psychiatric symptom profiles in schizophrenia and affective psychoses. Psychiatry Res. 2018;265:19-24. doi:10.1016/j.psychres.2018.04.015

118. Bramness JG, Gundersen $\varnothing \mathrm{H}$, Guterstam J, et al. Amphetamine-induced psychosis—a separate diagnostic entity or primary psychosis triggered in the vulnerable? BMC Psychiatry. 2012;12:221. doi:10.1186/1471-244X-12-221

119. Moran LV, Ongur D, Hsu J, Castro VM, Perlis RH, Schneeweiss S. Psychosis with methylphenidate or amphetamine in patients with ADHD. N Engl J Med.2019;380(12):1128-1138. doi:10.1056/NEJMoa1813751

120. Kaar SJ, Gobjila C, Butler E, Henderson C, Howes OD. Making decisions about antipsychotics: a qualitative study of patient experience and the development of a decision aid. BMC Psychiatry. 2019;19(1):309. doi:10.1186/s12888-019-2304-3

121. Kaar SJ, Natesan S, McCutcheon R, Howes OD. Antipsychotics: mechanisms underlying clinical response and side-effects and novel treatment approaches based on pathophysiology. Neuropharmacology. 2020;172:107704. doi:10.1016/j.neuropharm.2019.107704 
122. Weyandt L, White TL, Gudmundsdottir BG, et al. Neurocognitive, autonomic, and mood effects of adderall: a pilot study of healthy college students. Pharmacy. 2018;6(3):58. doi:10.3390/ pharmacy6030058

123. Arria AM, Caldeira KM, Vincent KB, et al. Do college students improve their grades by using prescription stimulants nonmedically? Addict Behav. 2017;65:245-249. doi:doi:10.1016/j. addbeh.2016.07.016

124. Berridge CW, Devilbiss DM. Psychostimulants as cognitive enhancers: the prefrontal cortex, catecholamines, and attention-deficit/hyperactivity disorder. Biol Psychiatry. 2011;69(12):e101-e111. doi:10.1016/j.biopsych.2010.06.023

125. Lam AP, Matthies S, Graf E, et al. Long-term effects of multimodal treatment on adult attention-deficit/hyperactivity disorder symptoms: follow-up analysis of the COMPAS trial. JAMA Netw Open. 2019;2(5):e194980. doi:10.1001/jamanetworkopen.2019.4980

126. Pievsky MA, McGrath RE. Neurocognitive effects of methylphenidate in adults with attention-deficit/hyperactivity disorder: a meta-analysis. Neurosci Biobehav Rev. 2018;90:447-455. doi:10.1016/j.neubiorev.2018.05.012

127. Loskutova NY, Waterman J, Callen E, Staton EW, Bullard E, Shields J. Knowledge, attitudes, and practice patterns of health professionals toward medical and non-medical stimulant use by young adults. J Am Board Fam Med. 2020;33(1):59-70. doi:10.3122/jabfm.2020.01.190071

128. Philipsen A, Jans T, Matthies S, et al. Multimodal treatment of adult ADHD: a randomized controlled multicentre trial (COMPAS). ADHD Atten Deficit Hyperact Disord. 2015;7:1-119. doi:10.1007/s12402-015-0169-y

129. MTA Cooperative Group. A 14-month randomized clinical trial of treatment strategies for attention-deficit/hyperactivity disorder. Arch Gen Psychiatry. 1999;56(12):1073-1086. doi:10.1001/archpsyc.56.12.1073

130. Cortese S, Adamo N, Del Giovane C, et al. Comparative efficacy and tolerability of medications for attention-deficit hyperactivity disorder in children, adolescents, and adults: a systematic review and network meta-analysis. Lancet Psychiatry. 2018;5(9):727-738. doi:10.1016/ S2215-0366(18)30269-4

131. Coghill D. Debate: are stimulant medications for attention-deficit/hyperactivity disorder effective in the long-term? J Am Acad Child Adolesc Psychiatry. 2019;58(10):938-939. doi:10.1016/j. jaac.2019.07.002

132. Swanson JM. Debate: are stimulant medications for attention-deficit/hyperactivity disorder effective in the long term? J Am Acad Child Adolesc Psychiatry. 2019;58(10):936-938. doi:10.1016/j. jaac.2019.07.001

133. Matthijssen A-FM, Dietrich A, Bierens M, et al. Continued benefits of methylphenidate in ADHD after 2 years in clinical practice: a randomized placebo-controlled discontinuation study. Am J Psychiatry. 2019;176(9):754-762. doi:10.1176/appi.ajp.2019.18111296

134. Pliszka SR. Is there long-term benefit from stimulant treatment for ADHD? Am J Psychiatry. 2019;176(9):685-686. doi:10.1176/appi.ajp.2019.19070681

(c) 2021 Author(s)

This is an open-access article distributed under the terms of the Creative Commons Attribution 4.0 International license, which permits anyone to download, copy, distribute, display, or adapt the text without asking for permission, provided that the creator(s) are given full credit.

ISSN 2470-9727 